\title{
Parametric Study on Self-centering Precast Concrete Frames with Hysteretic Dampers
}

\author{
Yadong $\mathrm{Li}^{1}$, Fangfang Geng ${ }^{1,2^{*}}$, Youliang Ding ${ }^{1}$, Libin Wang ${ }^{3}$ \\ ${ }^{1}$ Key Laboratory of Concrete and Prestressed Concrete, Structures of the Ministry of Education, Southeast University, Nanjing 210096, \\ China \\ 2 School of Architecture Engineering, Nanjing Institute of Technology, Nanjing 211167, China \\ ${ }^{3}$ College of Civil Engineering, Nanjing Forestry University, Nanjing 210037, China \\ * Corresponding author, e-mail: j00000002962@njit.edu.cn
}

Received: 13 November 2019, Accepted: 07 March 2021, Published online: 24 March 2021

\begin{abstract}
The self-centering precast concrete frame structure combines the advantages of industrialization and low earthquake damage, and its energy dissipation capacity and seismic performance have always been the focus of research. This paper proposed a kind of selfcentering precast concrete frame with hysteretic dampers (SCPCHD). Its modular design makes the energy dissipation device and components easy to repair and replace. In order to obtain the optimal design, the finite element models of SCPCHD frames with different layout types of post-tensioned (PT) tendons and different shapes of hysteretic dampers are established, and the elastoplastic dynamic time-history analyses are carried out. The results show that the layout types and vertical margin of PT tendons have little effect on the displacement response of the frame structure. Compared to linear PT tendons, polygonal PT tendons can better bear the bending moment of the beam and reduce the stress of longitudinal reinforcements in the beam. The reduce effect of shortening the vertical margin on the tensile damage of beam concrete is obvious in the frame with polygonal PT tendons, but not obvious in the frame with linear PT tendons. Rational design of the prestressing force also plays a crucial role in the energy dissipation capacity of SCPCHD frames.
\end{abstract}

Keywords

self-centering, precast concrete frame, unbonded post-tensioning, seismic response, hysteretic damper, parametric study

\section{Introduction}

The traditional reinforced concrete frame structure is widely used because of its good ductility and low cost. In the past few earthquakes, huge loss of life and property has occurred, which has made the defects of the traditional reinforced concrete frame structure more prominent. The Northridge earthquake in 1994, the Wenchuan earthquake in 2008 and the Canterbury earthquake in 2011 all confirmed that the severe damage and irreversible deformation caused great difficulties to rescue [1-4]. These severe damages and deformation will also greatly affect the recovery of urban functions, including the rehabilitation and reconstruction of post-disaster buildings, which will cause incalculable negative effects.

In order to reduce the damage and residual deformation of the reinforced concrete frame structure, the self-centering precast concrete frame structure is designed and continuously improved for its energy dissipation performance.
Stone et al. [5] tested 10 hybrid precast concrete beamto-column connections, including mild steel used to dissipate energy and post-tensioning steel used to provide the required shear resistance, and the results show that the hybrid precast connection can be designed to match or exceed the performance of a monolithic connection in terms of energy dissipation, strength, and drift capacity. Morgen and Kurama [6] tested large-scale beam-column specimens under reversed cyclic loading with and without novel friction dampers, and the results showed that the dampers can be designed to provide a significant amount of supplemental energy dissipation to a frame, while the self-centering capability of the structure is preserved. Song et al. [7] and Guo et al. [8-10] experimentally studied the behavior of a self-centering moment resisting concrete frame with beam web friction devices under cyclic loading, and the energy dissipation capability of the 
self-centering frame system was directly influenced by the magnitude of the friction bolt forces. With the continuous research on the self-centering precast concrete frame structure, its energy dissipation performance has been significantly improved. As a new structure system that is different from the cast-in-place reinforced concrete frame structure, the self-centering precast concrete frame structure still needs further improvement and research.

The self-centering structure is between the traditional structure and the rocking structure. The rocking structure reflects the self-centering behavior in a more thorough way. Rocking columns, rocking shear walls, and rocking frames have the advantages of low cost and low damage. However, the traditional response spectrum analysis is not very suitable for the design of the rocking structure. Some studies have been carried out on the seismic performance and design methods of rocking structures [11, 12]. Also, some research on piecewise behavior are helpful to monitor the safety of self-centering structure and rocking structure $[13,14]$. The research on these resilient structures has been gradually expanded and deepened. In this paper, a novel self-centering precast concrete frame with hysteretic dampers (SCPCHD) was proposed. Hysteretic dampers located on both sides of the beam end provide energy dissipation capability. The modular design of energy dissipation devices makes them easy to upgrade and replace. The connection mode of components adopts dry connection, which is more in line with the development trend of building industrialization. In order to obtain the seismic response characteristics of SCPCHD frames with different design parameters, the finite element models were established by ABAQUS for the SCPCHD frames with different layout types of post-tensioned (PT) tendons and different shapes of hysteretic dampers, and the nonlinear dynamic time-history analyses were carried out to evaluate their influence on the seismic performance of SCPCHD frames.

\section{SCPCHD frames with different design parameters}

\subsection{The prototype structure and SCPCHD connection}

The prototype structure is a two-story, two-span SCPCHD frame structure located in China with a span of $6000 \mathrm{~mm}$ in both the X and Y directions and a height of $3600 \mathrm{~mm}$. The SCPCHD frame structure is designed according to Chinese Standard GB 50010-2010 [15] and GB 500112010 [16], and the basic design information is shown in Table 1. A frame of the SCPCHD frame structure is taken as the research object, as shown in Fig. 1. The main structural materials are $\mathrm{C} 40$ concrete and HRB400 reinforcement.
The joint connection and component details of the SCPCHD frame are shown in Fig. 2. The precast beam and the precast column are connected by the PT tendons that provide the self-centering capability, and the PT tendons and the hysteretic dampers jointly bear the beam end moment. The shear rod can roll and slide in the track of the shear bear to meet the reliable transmission of shear force under strong earthquakes. The hysteretic dampers distributed around the beam end are welded to the steel connectors and the steel plates embedded in the column, and the steel connectors are bolted to the sides of the beam end. Also, to reduce concrete damage caused by the interaction between beam and column, another steel plate is embedded at the beam end. The steel plate thickness of all steel components is $10 \mathrm{~mm}$. The nominal diameter of unbonded

Table 1 The basic design information

\begin{tabular}{lc}
\hline Description & Quantity \\
\hline Dead load & $5.0 \mathrm{kN} / \mathrm{m}^{2}$ \\
Live load & $2.0 \mathrm{kN} / \mathrm{m}^{2}$ \\
Seismic design intensity & 7 \\
Soil condition & Type IV \\
Design peak ground acceleration (PGA) & $0.10 \mathrm{~g}$ \\
\hline
\end{tabular}

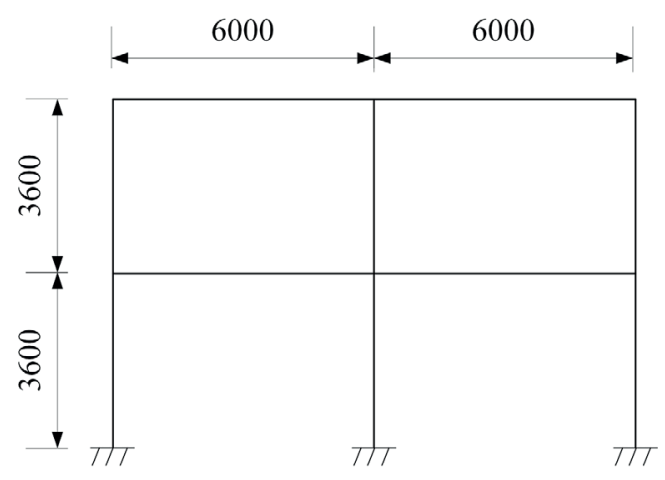

(a)
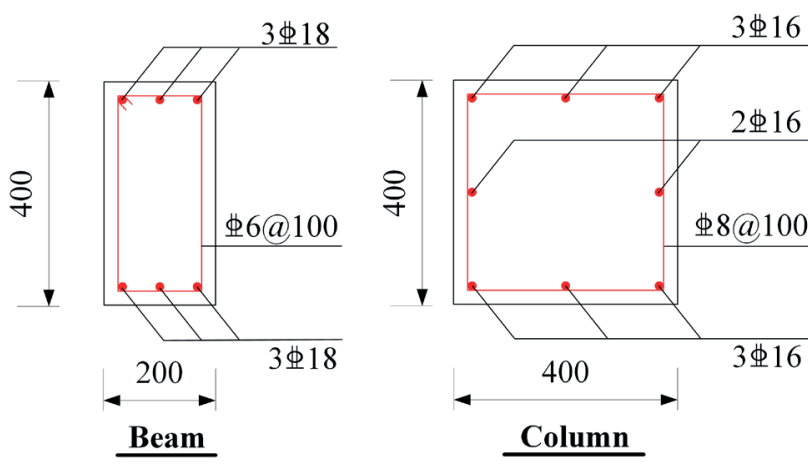

(b)

Fig. 1 Design of SCPCHD frame (unit: mm): (a) frame size; (b) section reinforcement 


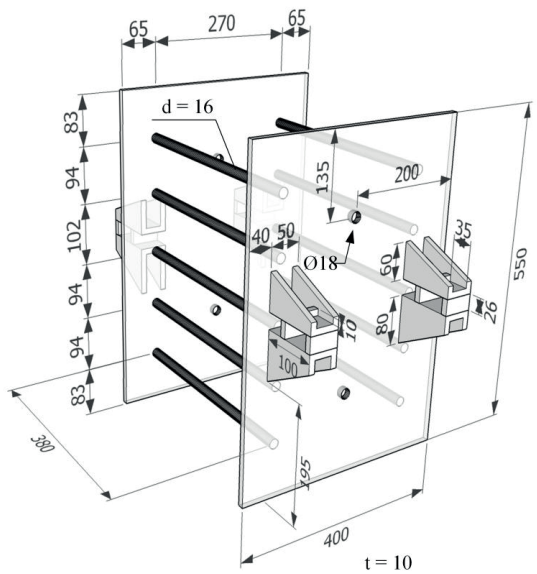

Steel plate (interior column)

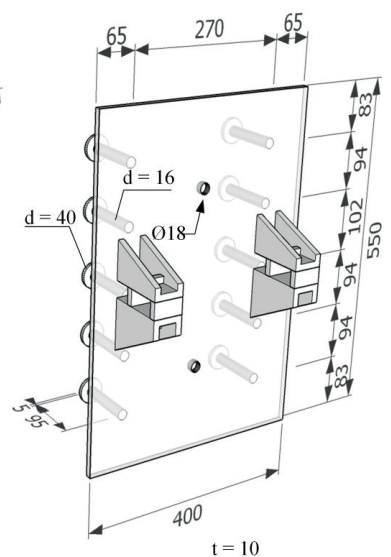

Steel plate (boundary column)

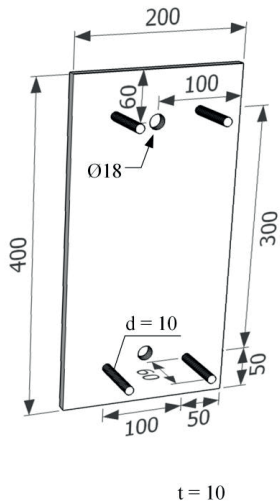

$t=10$

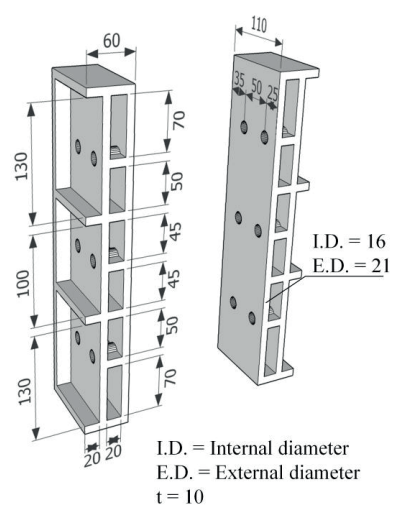

Steel connector

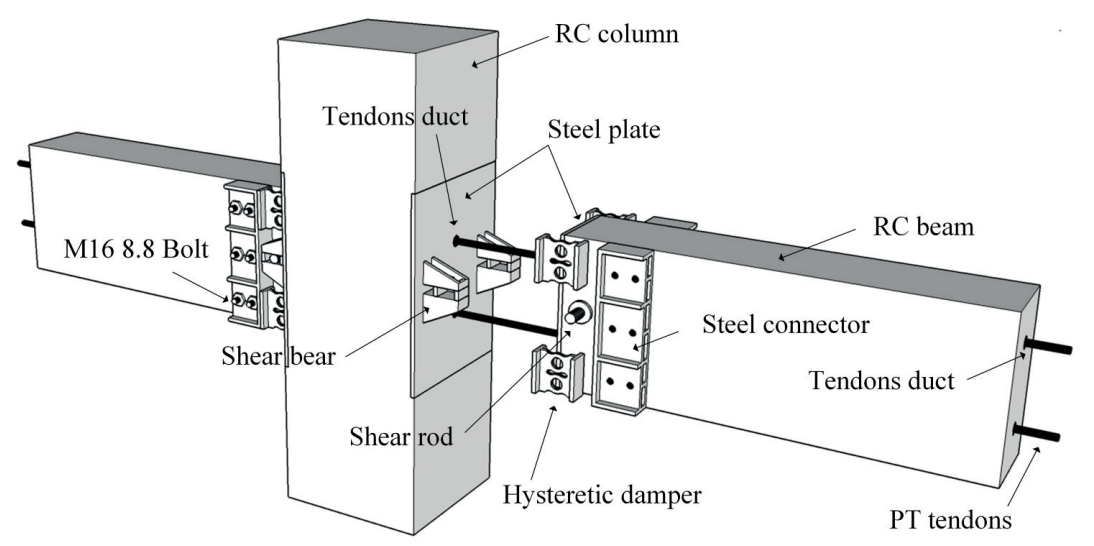

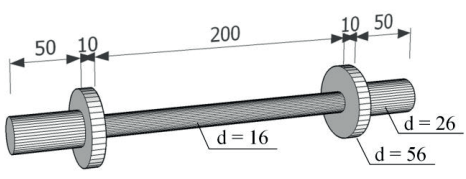

Shear rod

Fig. 2 The SCPCHD connection and component details

PT tendons is $15.2 \mathrm{~mm}$ and its ultimate tensile strength is $1860 \mathrm{Mpa}$. All steel devices except hysteretic dampers use Q345 steel with the nominal yield strength of $345 \mathrm{MPa}$.

The SCPCHD frame has the characteristics of industrialization and modularization. The precast concrete members and steel components of the frame are respectively connected by PT tendons and welding, which will greatly save construction time and labor cost. The hysteretic dampers can be easily replaced after damage. If novel energy dissipation materials and equipment are developed, they can be replaced and upgraded.

\subsection{SCPCHD frames with different layout types of PT tendons}

In order to obtain a better design and the influence of different PT tendons arrangements on the seismic response of the SCPCHD frame, five different layout types of PT tendons were designed, as shown in Fig. 3. Because the PT tendons in the SCPCHD frame are unbonded, compared with the linear PT tendons, the polygonal PT tendons should be able to significantly improve the bending capacity of precast beams. The case with one polygonal PT tendon with a vertical margin of $60 \mathrm{~mm}$ is named B1PT060. The case with two linear PT tendons with the same vertical margin and prestressing force as B1PT060 is named B2PT060. Because of the difference of the shape of PT tendons, it is difficult to make a strict quantitative comparative analysis between the two cases. The improvement effect of the

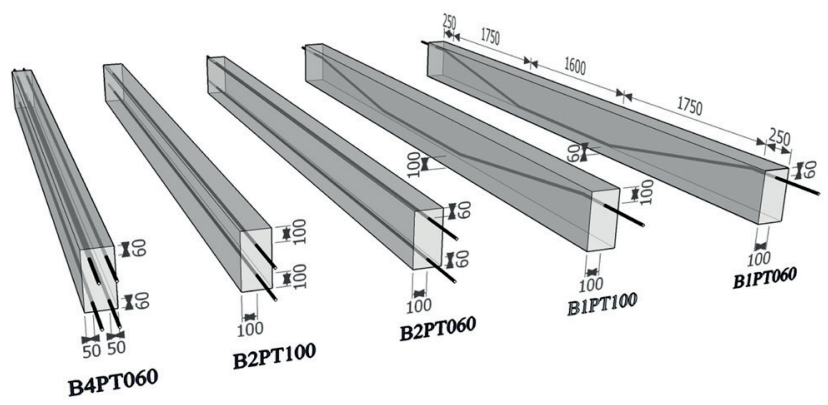

Fig. 3 Different layout types of PT tendons 
polygonal PT tendons on the stress state of precast beams is qualitatively analyzed by comparing the responses of B1PT060 and B2PT060. The cases of changing the vertical margins of B1PT060 and B2PT060 to $100 \mathrm{~mm}$ are named B1PT100 and B2PT100, and the influence of vertical margins on structural response under different PT tendons shapes is obtained by comparative analysis. The case with doubled PT tendons of B2PT060 is named B4PT060, and the influence of prestressing force on structural response is obtained through comparative analysis. The arrangement details of PT tendons in different cases are shown in Table 2. The research results will be used to further improve and optimize the design of SCPCHD frame.

\subsection{SCPCHD frames with different hysteretic dampers}

The energy dissipation of the SCPCHD frame relies primarily on hysteretic dampers at the top and bottom of beam ends. Hysteretic dampers are inexpensive to manufacture and easy to maintain and replace, which use Q235 steel with a nominal yield strength of $235 \mathrm{MPa}$. To analyze the energy dissipation capacity of different hysteretic dampers and the influence on the seismic response of frame, circular opening hysteretic dampers and strip opening hysteretic dampers were designed as shown in Fig. 4. The steel plate thickness of hysteretic dampers is $10 \mathrm{~mm}$.

\section{Numerical study}

\subsection{Modelling approach}

The finite element (FE) models of SCPCHD frames were built using ABAQUS. In order to obtain comprehensive and accurate analysis results, almost all components were built using C3D8R solid elements. Reinforcements and PT tendons were built using T3D2 truss elements. The constitutive model of concrete was taken from Chinese Standard GB 50010-2010 [15], considering the damaged plasticity concrete behavior. The steel devices, reinforcements and PT tendons adopted bilinear elastoplastic constitutive models.

The prestressing force was carried out by using the "cooling method" $[17,18]$. The "cooling method" was to arrange a temperature field on PT tendons to cool down,
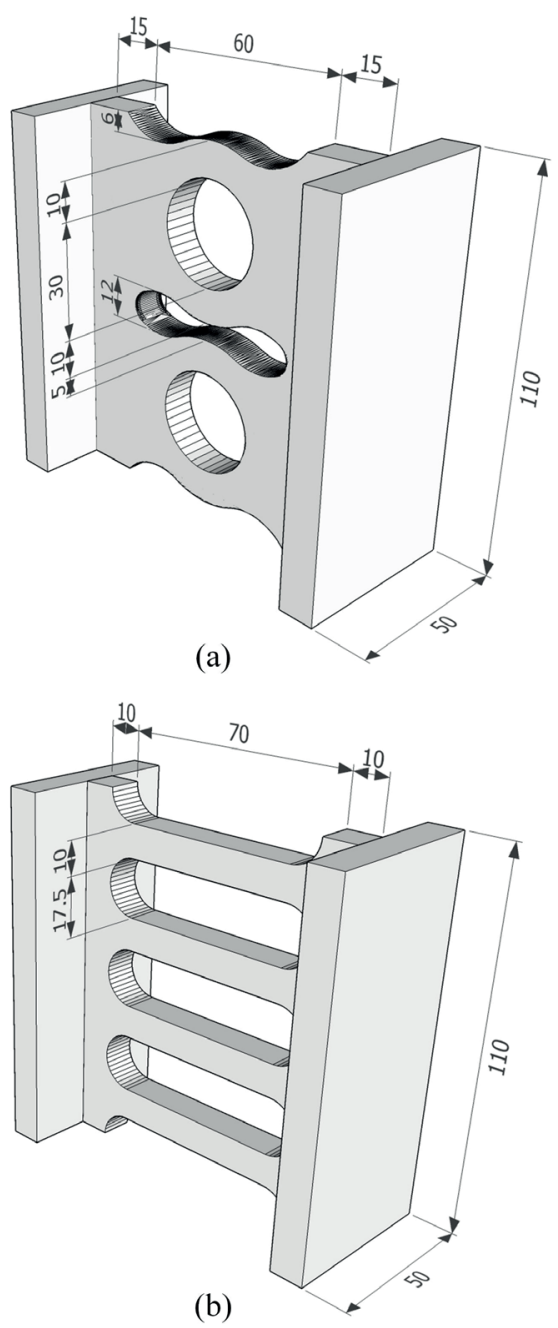

Fig. 4 Different shapes of hysteretic dampers

and the PT tendons shrank to obtain prestressing force. The unbonded behavior of PT tendons was simulated by SPRING2 elements [17, 19]. SPRING2 elements were densely arranged on PT tendons, and each node on PT tendons was connected to an adjacent concrete node. These spring elements only limited the vertical degree of freedom and the stiffness was infinite.

SCPCHD frame was assembled by post-tensioning. Therefore, the interaction between the beam and column members was much more complicated than the RC frame. Therefore, in order to realistically simulate the interaction

Table 2 Details of different layout types of PT tendons

\begin{tabular}{lcccc}
\hline Name & Numbers of PT tendons & Vertical margin of PT tendons & Horizontal margin of PT tendons & Shape of PT tendons \\
\hline B4PT060 & 4 & 60 & 50 & 100 \\
B2PT100 & 2 & 100 & 100 & Line \\
B2PT060 & 2 & 60 & 100 & 100 \\
B1PT100 & 1 & 100 & 60 & Pine \\
B1PT060 & 1 & Polyline & 100 \\
\hline
\end{tabular}


of components, a large number of contact pairs were used. The main contact pairs include beam-column contact pairs and shear transfer contact pairs. The beam-column contact pairs were used to achieve the gap at the beam end and the pressure of the contact surface, as shown in Fig. 5(a). The shear transfer contact pairs were used to realize the sliding and rolling of the shear rod on the shear bear, so as to truly simulate the reliable transfer of shear force at beam end when subjected to large deformation, as shown in Fig. 5(b).

\subsection{Analytical models}

Seismic responses of SCPCHD frames with different design parameters were compared by dynamic time-history analyses. El-Centro (N-S) ground motion record was adopted for time-history analyses according to the rare earthquake design response spectrum. The design and earthquake acceleration response spectra are shown in Fig. 6 , and the damping ratio is 0.05 . In order to obtain the residual deformation of the frame and reduce calculation cost, a 10-second record containing the peak acceleration of El-Centro seismic wave was selected and a 10-second free vibration was added as the input ground motion. The input ground motions were scaled to PGA of $0.1 \mathrm{~g}$ and $0.22 \mathrm{~g}$, corresponding to the design basis earthquake (DBE) and the maximum considered earthquake (MCE) of 7-intensity in China according to the Chinese Code for Seismic Design of Buildings [16]. A Rayleigh damping of $5 \%$ was assumed for the first and second modes.

Considering the different arrangements of PT tendons and different shapes of hysteretic dampers, as well as the seismic action of different intensities, 12 analytical models were established, as shown in Table 3. Model 1 to model 10 were used to analyze the influence of different PT tendons arrangements on the seismic responses of SCPCHD frames under different seismic intensities. Models 11 and 12 were compared with models 1 and 2 to analyze the influence of different hysteretic dampers on the energy dissipation capability of SCPCHD frames.

\section{Dynamic time-history analyses 4.1 Global responses}

The maximum and residual story drift ratios of all analytical models are shown in Table 4. The layout of PT tendons and the type of hysteretic dampers had different effects on the displacement responses of these frames. By comparing the displacement responses of the B1PT060C and B1PT100C frame, the vertical margin of PT tendons had

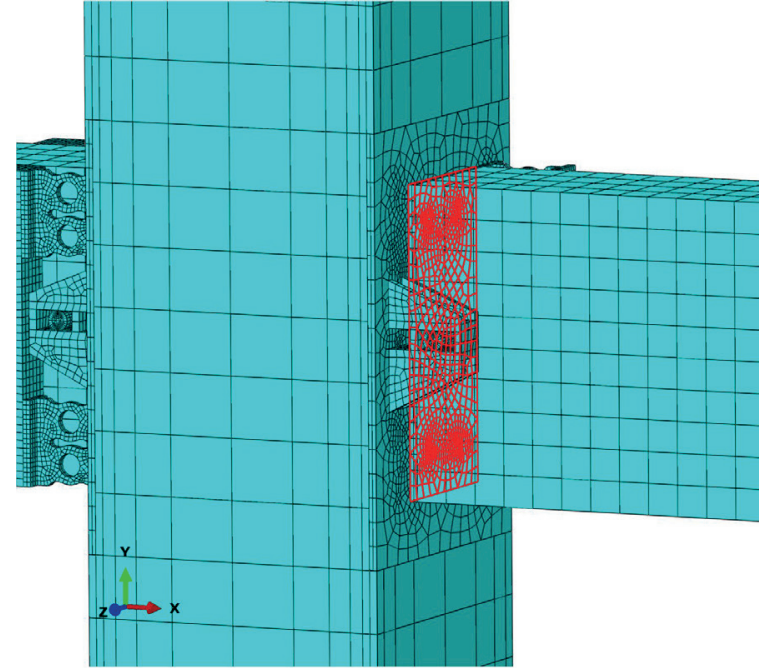

(a)

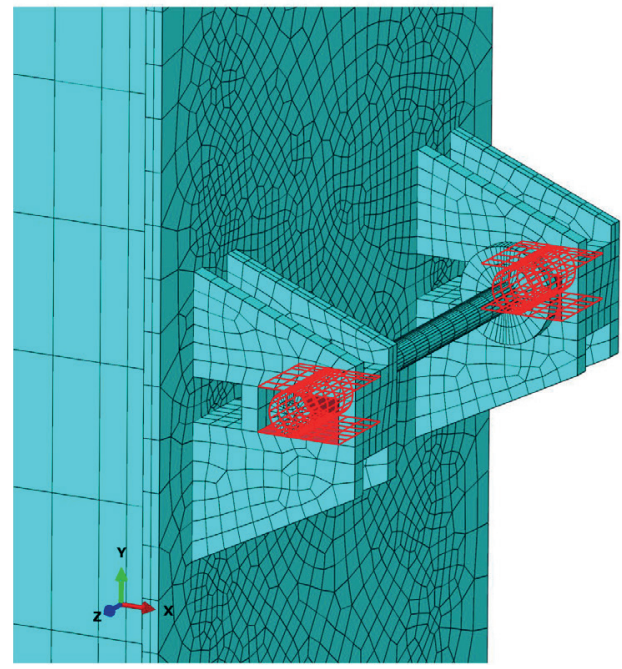

(b)

Fig. 5 Main contact pairs: (a) Beam-column contact pairs; (b) Shear transfer contact pairs

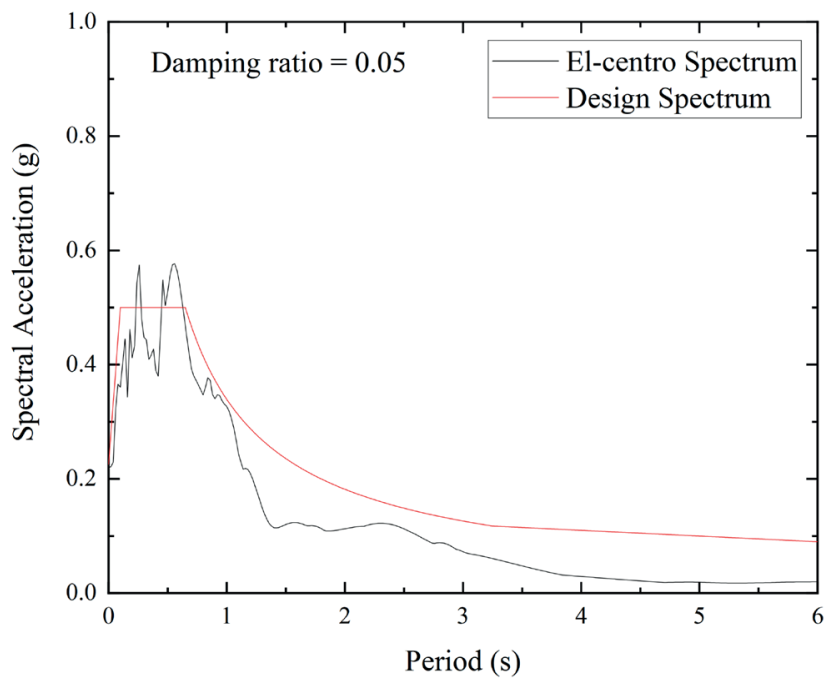

Fig. 6 Design and earthquake acceleration response spectra 
Table 3 Analytical models

\begin{tabular}{llcc}
\hline ID & Frame type & PGA $(\mathrm{g})$ & Shape of hysteretic dampers \\
\hline 1 & B1PT060C & 0.1 & Circular opening \\
2 & & 0.22 & \\
3 & & 0.1 & Circular opening \\
4 & B1PT100C & 0.22 & \\
5 & & 0.1 & Circular opening \\
6 & B2PT060C & 0.22 & \\
7 & & 0.1 & Circular opening \\
8 & B2PT100C & 0.22 & \\
9 & & 0.1 & Circular opening \\
10 & B4PT060C & 0.22 & Strip opening \\
11 & & 0.1 & \\
12 & B1PT060S & 0.22 & \\
\hline
\end{tabular}

a small effect on the maximum and residual story drift ratios of the frames using polygonal PT tendons. Under a PGA of $0.1 \mathrm{~g}$, the maximum and residual story drift ratios of the first and second stories of the B1PT100C frame with a vertical margin of $100 \mathrm{~mm}$ increased by $4.68 \%$ and $4.39 \%$, respectively, compared with the B1PT060C frame with a vertical margin of $60 \mathrm{~mm}$. Under a PGA of $0.22 \mathrm{~g}$, the displacement responses of both frames were basically the same. By comparing the displacement responses of the B2PT060C and B2PT100C frames, the vertical margin of the PT tendons had little effect on the maximum and residual story drift ratios of the frames using linear PT tendons.

Besides, there was little difference in the maximum and residual story drift ratios between the B1PT060C frame with one polygonal PT tendon and the B2PT060C frame with two linear PT tendons, and the residual story drift ratio of the B2PT060C frame was slightly larger than that of the B1PT060C frame. Therefore, the layout and vertical margin of PT tendons had little effect on displacement responses of the frame structure.

The inter-story displacement response time-history curves of the B2PT060C and B4PT060C frames are shown in Fig. 7. Under a PGA of $0.1 \mathrm{~g}$, the maximum displacements of the first and second story of the B4PT060C frame were $93.42 \%$ and $91.57 \%$ of that of the B2PT060C frame, respectively. Under a PGA of $0.22 \mathrm{~g}$, the maximum displacements of the first and second story of the B4PT060C frame were $94.47 \%$ and $91.78 \%$ of that of the B2PT060C frame, respectively. Therefore, the displacement response of frame structure can be reduced by increasing the resultant force of PT tendons, but the reduction is not significant.

The inter-story displacement response time-history curves of the B1PT060C and B1PT060S frames are shown in Fig. 8. Under a PGA of $0.1 \mathrm{~g}$, the displacement response time-history curves of both frames were basically the same. Under a PGA of $0.22 \mathrm{~g}$, the displacement response time-history curves of both frames were basically the same before reaching the peak displacement, but then the difference began to appear. In the time period of 6 seconds to 8 seconds, the displacement response of the B1PT060S frame was significantly larger than that of the B1PT060C frame, which was caused by the out-of-plane buckling of strip opening hysteretic dampers in the B1PT060S frame. Also, the residual inter-story displacements of the first and second story of the B1PT060S frame were 5.01 times and 1.33 times that of the B1PT060C frame, respectively.

Table 4 Maximum and residual story drift ratios

\begin{tabular}{|c|c|c|c|c|c|c|}
\hline \multirow{2}{*}{ Analytical models } & \multirow{2}{*}{ Frame type } & \multirow{2}{*}{ PGA (g) } & \multicolumn{2}{|c|}{ Maximum story drift ratios } & \multicolumn{2}{|c|}{ Residual story drift ratios } \\
\hline & & & $1 \mathrm{~F}$ & $2 \mathrm{~F}$ & $1 \mathrm{~F}$ & $2 \mathrm{~F}$ \\
\hline 1 & \multirow{2}{*}{ В1РТ060C } & 0.1 & $0.248 \%$ & $0.248 \%$ & $0.002 \%$ & $0.004 \%$ \\
\hline 2 & & 0.22 & $0.561 \%$ & $0.580 \%$ & $0.011 \%$ & $0.012 \%$ \\
\hline 3 & \multirow{2}{*}{ B1PT100C } & 0.1 & $0.259 \%$ & $0.259 \%$ & $0.003 \%$ & $0.005 \%$ \\
\hline 4 & & 0.22 & $0.554 \%$ & $0.577 \%$ & $0.011 \%$ & $0.013 \%$ \\
\hline 5 & \multirow{2}{*}{ В2РТ060C } & 0.1 & $0.249 \%$ & $0.248 \%$ & $0.018 \%$ & $0.003 \%$ \\
\hline 6 & & 0.22 & $0.564 \%$ & $0.564 \%$ & $0.027 \%$ & $0.008 \%$ \\
\hline 7 & \multirow{2}{*}{ B2PT100C } & 0.1 & $0.248 \%$ & $0.248 \%$ & $0.018 \%$ & $0.003 \%$ \\
\hline 8 & & 0.22 & $0.562 \%$ & $0.564 \%$ & $0.029 \%$ & $0.009 \%$ \\
\hline 9 & \multirow{2}{*}{ B4PT060C } & 0.1 & $0.232 \%$ & $0.227 \%$ & $0.021 \%$ & $0.002 \%$ \\
\hline 10 & & 0.22 & $0.533 \%$ & $0.518 \%$ & $0.041 \%$ & $0.003 \%$ \\
\hline 11 & \multirow{2}{*}{ B1PT060S } & 0.1 & $0.246 \%$ & $0.249 \%$ & $0.012 \%$ & $0.013 \%$ \\
\hline 12 & & 0.22 & $0.566 \%$ & $0.571 \%$ & $0.056 \%$ & $0.017 \%$ \\
\hline
\end{tabular}




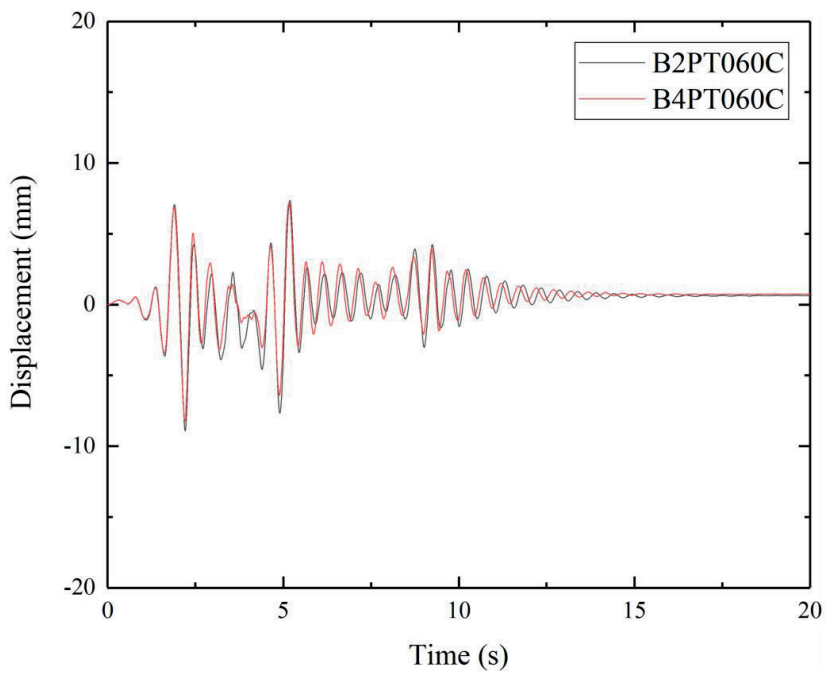

(a)

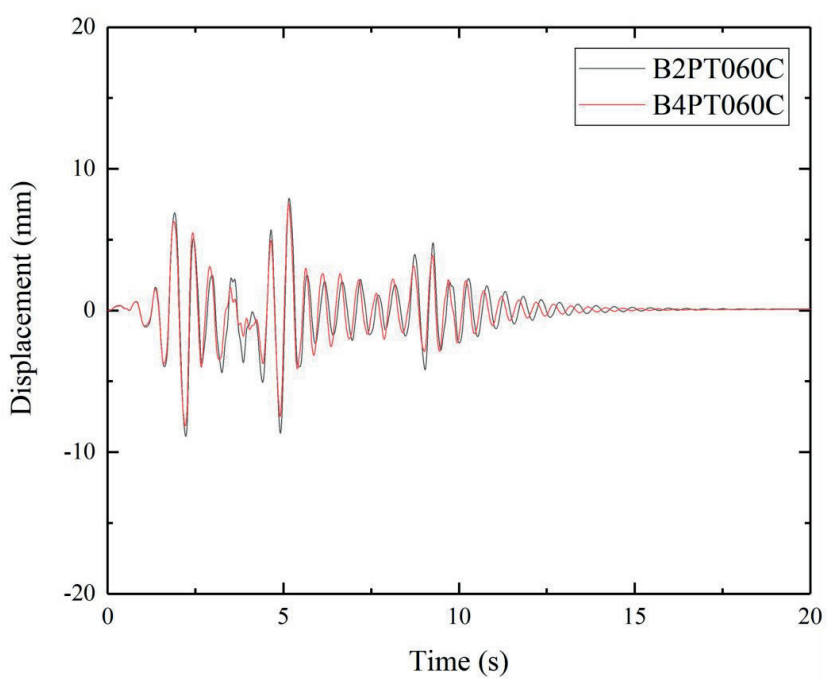

(c)

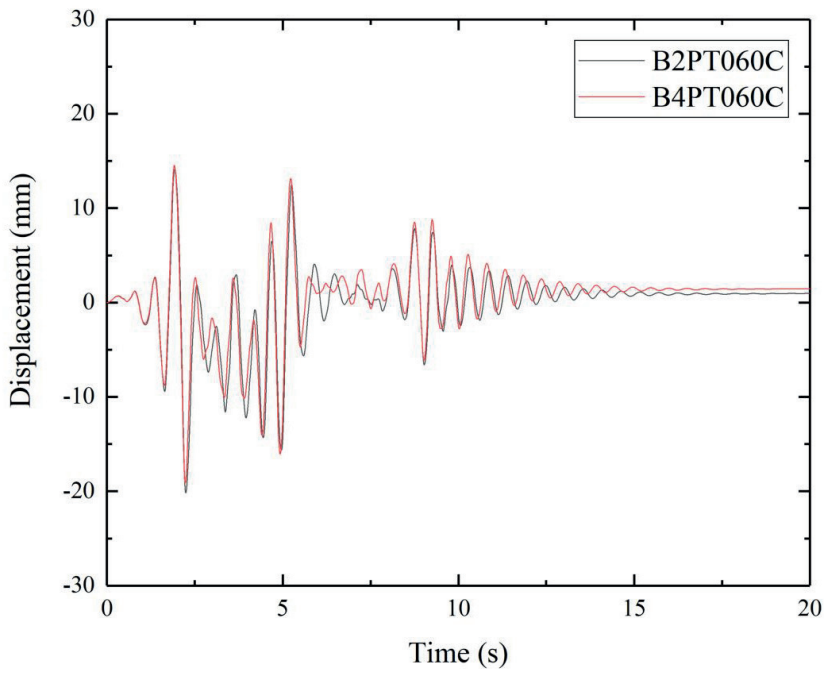

(b)

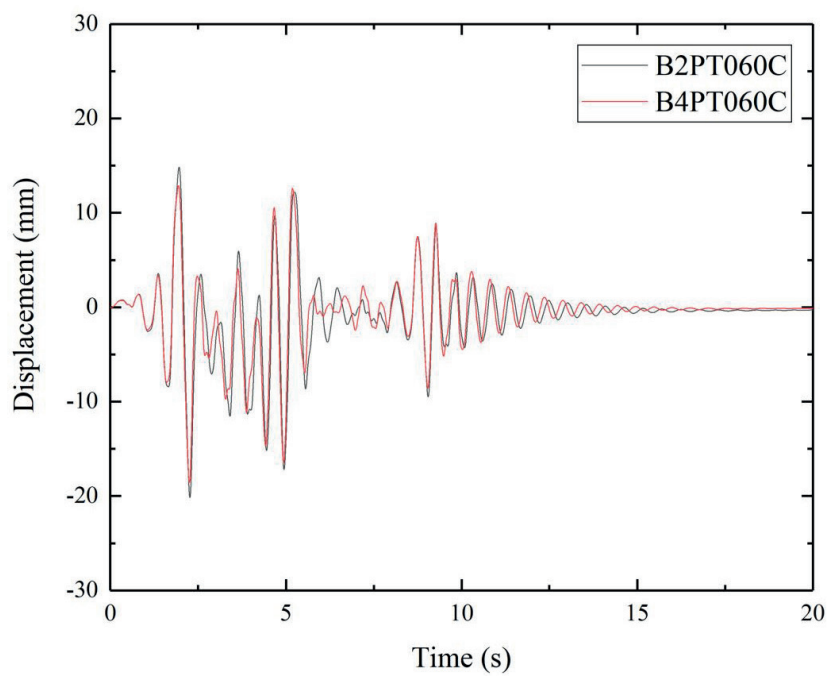

(d)

Fig. 7 Inter-story displacement response time-history curves of the B2PT060C frame and B4PT060C frame: (a) The first story (0.1 g);

(b) The first story $(0.22 \mathrm{~g})$; (c) The second story $(0.1 \mathrm{~g})$; (d) The second story $(0.22 \mathrm{~g})$

\subsection{Energy dissipation}

To further quantify the energy dissipation performance, the cumulative energy consumption of the aforementioned joints was calculated by the following formula [20-22]. $F_{i+1}$ and $F_{i}$ represented the restoring force of ${ }_{(i+1)}$ th point and the $i$ th point, respectively, $X_{i+1}$ and $X_{i}$ represented the corresponding displacements.

$E=\sum_{i=0}^{n} \frac{1}{2}\left(F_{i}+F_{i+1}\right)\left(X_{i+1}-X_{i}\right)$

It should be noted that the dissipated energy presented by this calculation method will decrease in some periods. This does not mean that the energy dissipation is decreasing, but because this calculation method shows the energy absorption and release during loading and unloading. This calculation method of energy dissipation is similar to the geometric meaning of integral, that is, the area enclosed by the load-displacement curve and $\mathrm{X}$-axis is subdivided into the sum of the areas of a large number of vertical bars to simplify the calculation. Taking one cycle as an example, the area value of the vertical bar is positive during loading and negative during unloading. The energy dissipation in a cycle can be obtained by summing the areas of all the vertical bars. Therefore, the energy dissipation value at the end of a loading cycle obtained by this method can represent the real energy dissipation in this loading cycle, that is, the area surrounded by the hysteresis loop. The energy dissipation at the end of loading obtained by this method represents the cumulative energy dissipation during the whole loading process. It is a simple and 


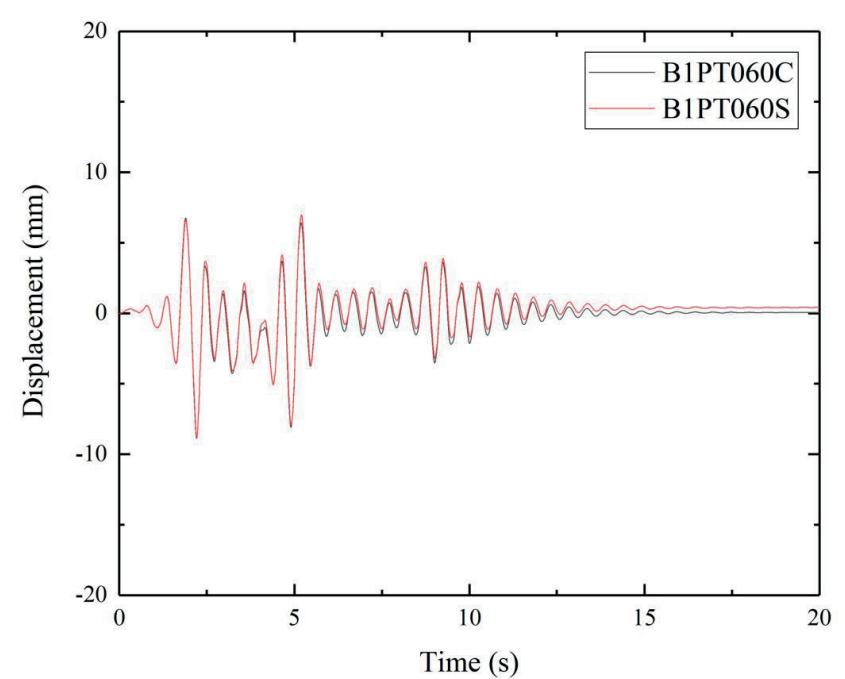

(a)

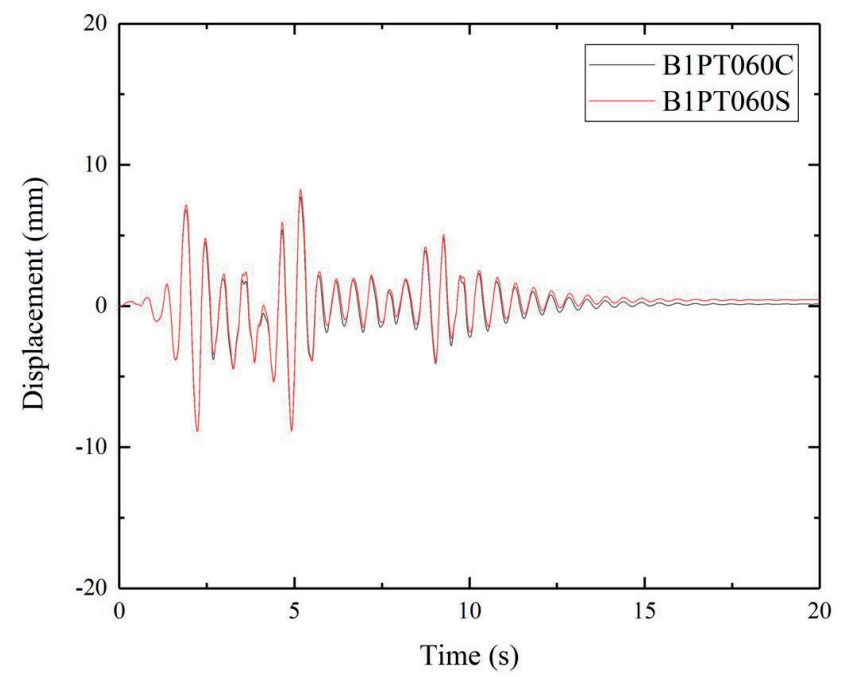

(c)

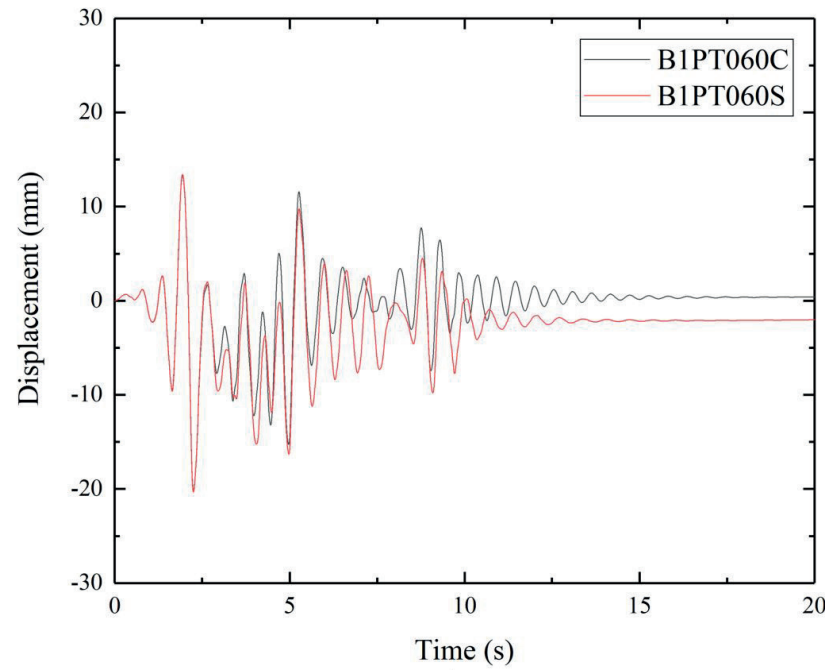

(b)

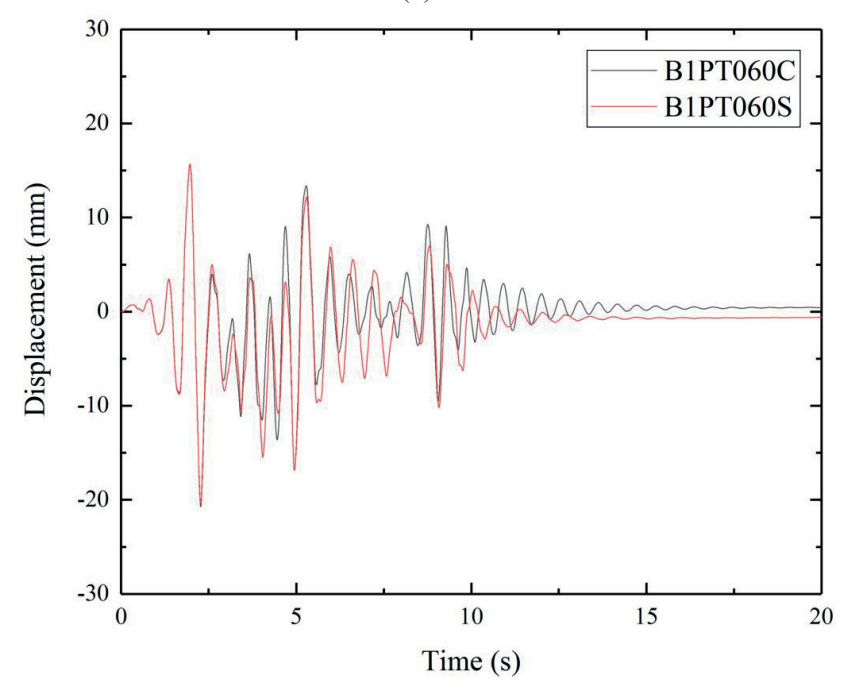

(d)

Fig. 8 Inter-story displacement response time-history curves of the B1PT060C frame and B1PT060S frame: (a) The first story (0.1 g);

(b) The first story $(0.22 \mathrm{~g})$; (c) The second story $(0.1 \mathrm{~g})$; (d) The second story $(0.22 \mathrm{~g})$.

convenient calculation method of energy dissipation based on a large number of continuous load-displacement data. Here, the cumulative energy dissipation at the end of loading is the main concern.

The energy dissipation time-history curves of the B1PT060C, B1PT100C, and B1PT060S frame joints are shown in Fig. 9. Under a PGA of $0.1 \mathrm{~g}$, the energy dissipation capability of the B1PT100C frame joint was the strongest, and there was little difference between the energy dissipation capability of the B1PT060C frame joint and the B1PT060S frame joint. Under the action of the design basis earthquake, the frame joint deformation was relatively small, and different hysteretic dampers had little effect on the energy dissipation performance of the frame joint. The B1PT100C frame with a vertical margin of $100 \mathrm{~mm}$ had better energy dissipation performance because of its relatively large joint rotation. Under a PGA of $0.22 \mathrm{~g}$, the energy dissipation capability of the B1PT060C and B1PT100C frame joints differed little. The energy dissipation of the B1PT060C frame joint was 3.35 times that of the B1PT060S frame joint, which was much larger than that of the B1PT060S frame joint. Therefore, the energy dissipation capability of the circular opening hysteretic dampers is significantly better than that of the strip opening hysteretic dampers.

As shown in Fig. 10. The energy dissipation time-history curves of the B2PT060C and B2PT100C frame joints with linear PT tendons were almost the same. Under a PGA of $0.22 \mathrm{~g}$, the energy dissipation of the B2PT060C frame joint was $63.39 \%$ of that of the B1PT060C frame joint. Therefore, the SCPCHD frame with one polygonal PT tendon had better energy dissipation than the SCPCHD 


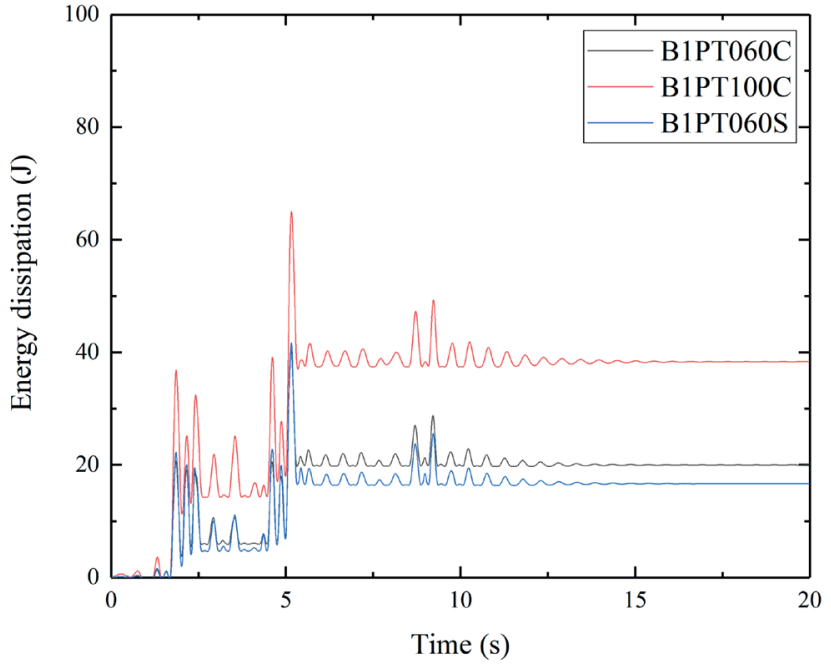

(a)

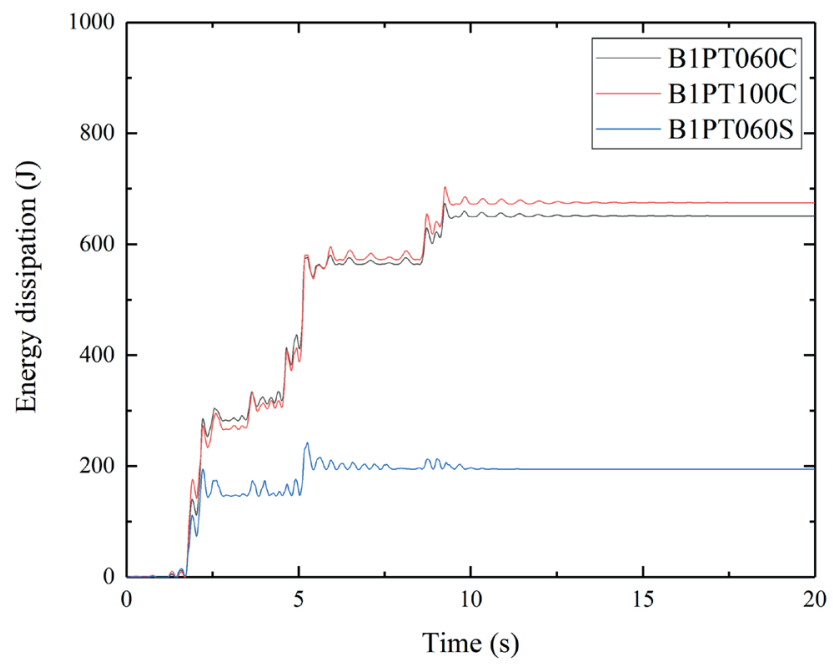

(b)

Fig. 9 Energy dissipation time-history curves of the B1PT060C, B1PT100C, and B1PT060S frame joints: (a) under a PGA of $0.1 \mathrm{~g}$;

(b) under a PGA of $0.22 \mathrm{~g}$

frame with two linear PT tendons. Under a PGA of $0.22 \mathrm{~g}$, the energy dissipation of the B4PT060C frame joint was $14.07 \%$ of that of the B2PT060C frame joint. The joint deformation of the B4PT060C frame with four PT tendons was relatively small, resulting in hysteretic dampers not playing a significant role. Therefore, the rational design of the prestressing force plays a crucial role in the energy dissipation capacity of the SCPCHD frame.

The hysteretic damper is the main energy dissipation component of the SCPCHD frame, and the stress state of hysteretic dampers can further reflect its energy dissipation capacity. Under a PGA of $0.22 \mathrm{~g}$, the relationships between the peak stress of hysteretic dampers and the joint rotation are shown in Fig. 11. The peak stress is the maximum value of the Mises stress at any point on

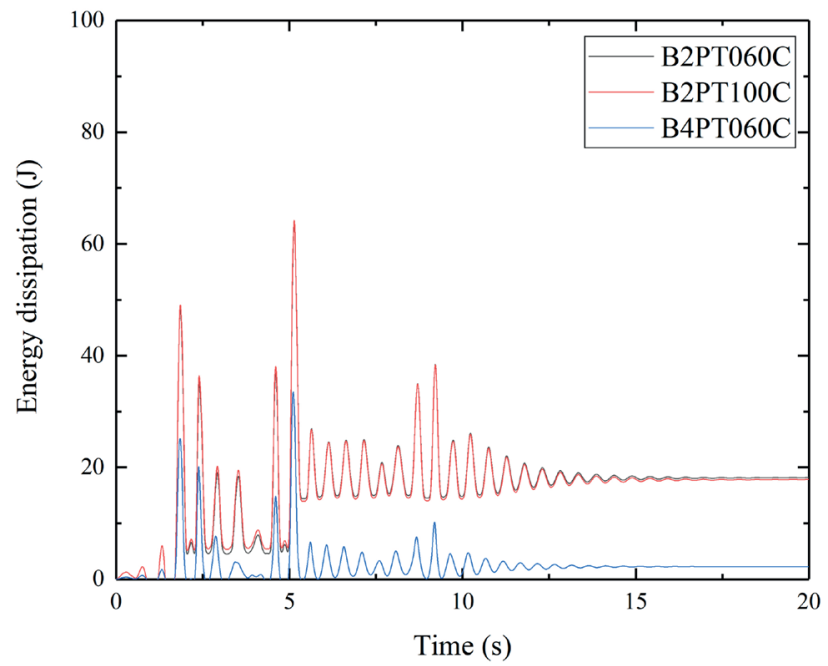

(a)

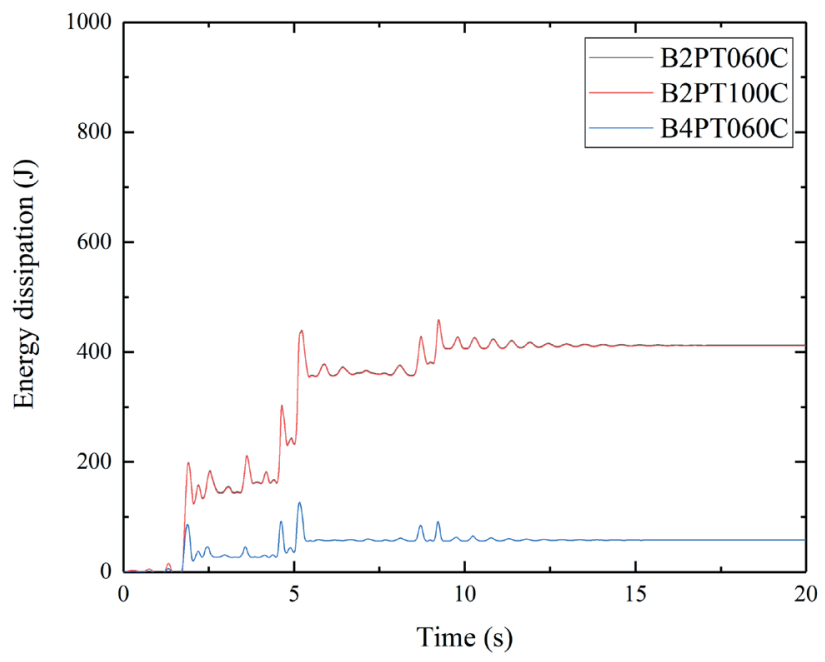

(b)

Fig. 10 Energy dissipation time-history curves of the B2PT060C, B2PT100C, and B4PT060C frame joints: (a) under a PGA of $0.1 \mathrm{~g}$;

(b) under a PGA of $0.22 \mathrm{~g}$

the entire hysteretic damper. The hysteretic damper with circular opening had good working performance, and its peak stress and joint rotation showed significant hysteresis characteristics. The hysteretic damper with strip opening exhibited significant instability. After the strip opening hysteretic damper first yielded and reached the maximum deformation, the peak stress and deformation mainly showed a multi-linear relationship, and there was almost no hysteretic characteristic. The initial peak stresses of strip opening hysteretic dampers located at the top and bottom were $77.17 \%$ and $69.09 \%$ of that of the circular opening hysteretic dampers, while the residual peak stresses of which were $164.59 \%$ and $96.64 \%$ of that of the circular opening hysteretic dampers. The initial peak stress of strip opening hysteretic damper was slightly smaller than that 


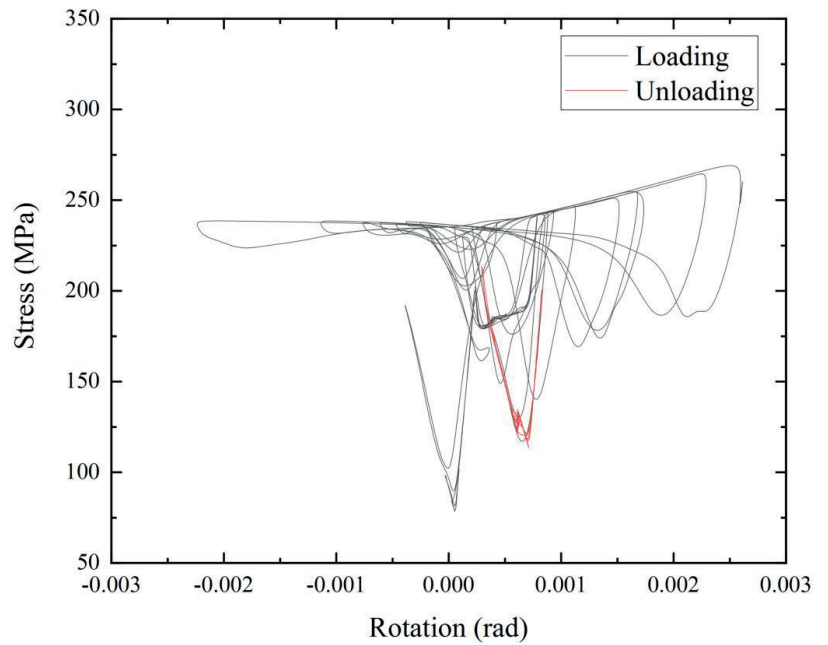

(a)

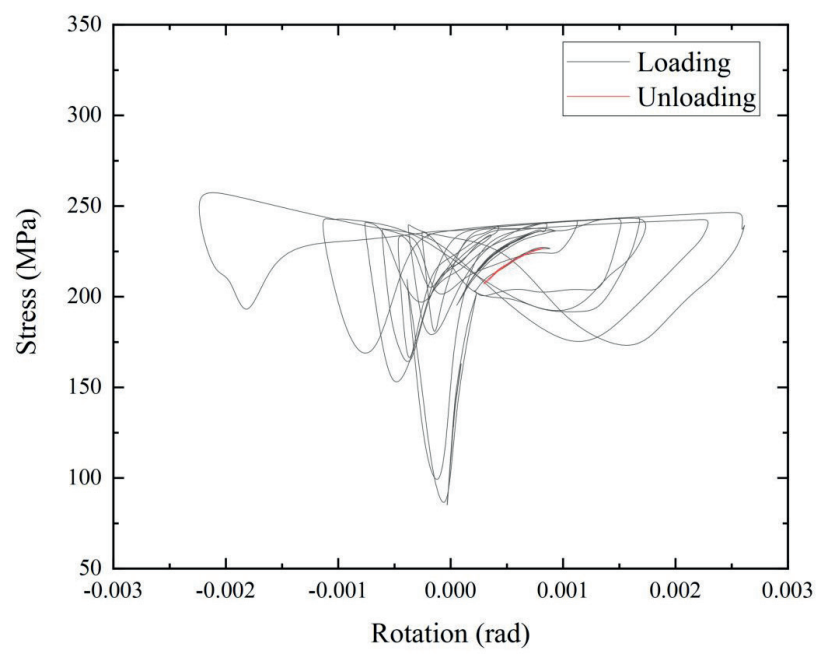

(c)

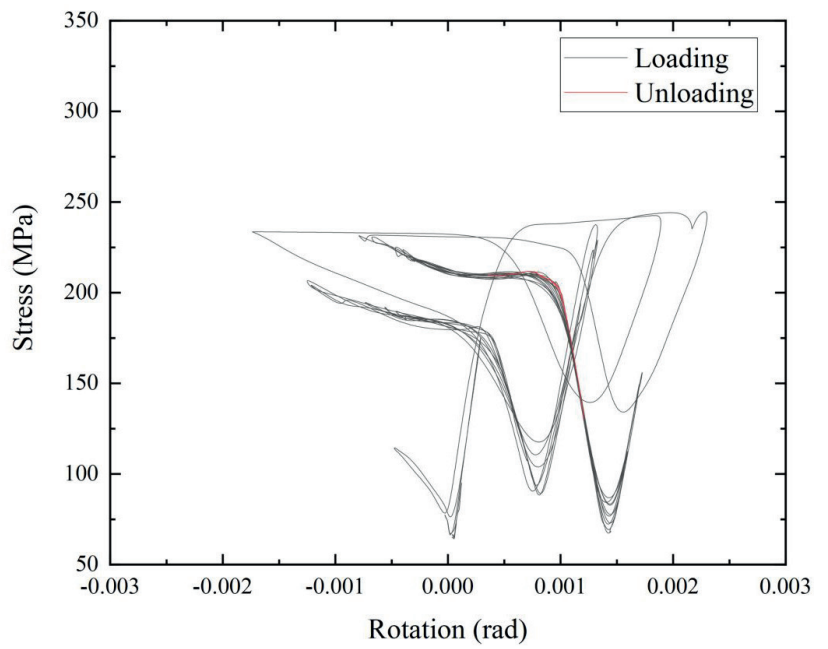

(b)

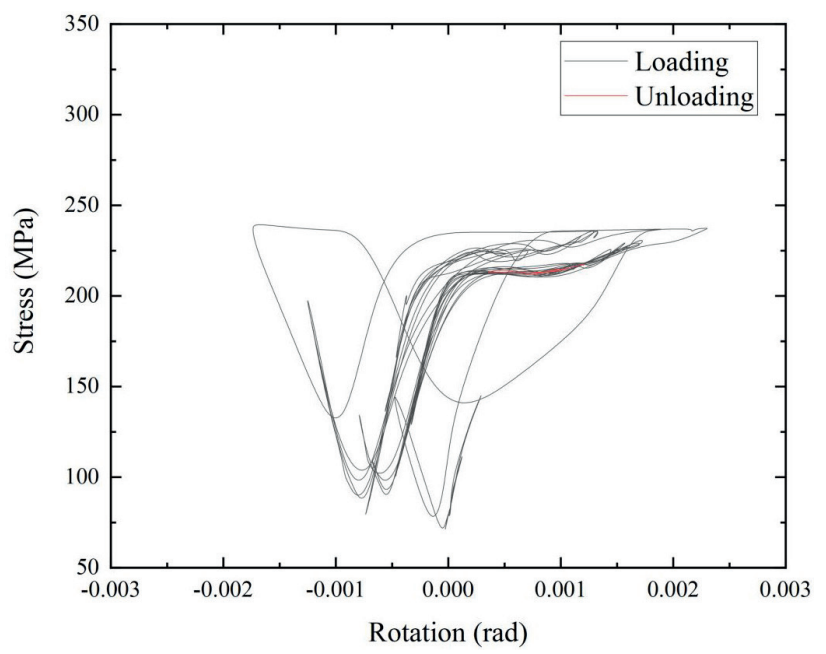

(d)

Fig. 11 The relationships between the peak stress of hysteretic damper and the joint rotation: (a) The top damper with circular opening;

(b) The top damper with strip opening; (c) The bottom damper with circular opening; (d) The bottom damper with strip opening

of the circular opening hysteretic damper, but the residual peak stress of strip opening hysteretic damper located at the top was significantly larger than that of the circular opening hysteretic damper.

In addition, hysteretic damper with strip opening also showed obvious out-of-plane deformation and thus partially lost its working performance. Under a PGA of $0.22 \mathrm{~g}$, the out-of-plane displacements of hysteretic dampers at the top and bottom of the intermediate beam-column joint on the first story are shown in Fig. 12. The out-of-plane displacement was taken from the midpoint of the top and bottom hysteretic dampers, respectively. The positive direction of the out-of-plane displacement is the positive direction of the z-axis shown in the figure. The peak out-of-plane displacements of top and bottom hysteretic dampers with strip opening were 56.17 times and 89.65 times that of the hysteretic dampers with circular opening, respectively.
The peak out-of-plane displacements of hysteretic dampers with circular opening at the top and bottom were $0.099 \mathrm{~mm}$ and $0.023 \mathrm{~mm}$ respectively, which were almost negligible, while the out-of-plane displacements of hysteretic dampers with strip opening were much larger than that of the hysteretic dampers with circular opening. For both hysteretic dampers, the out-of-plane displacements of the top hysteretic dampers were larger than that of the bottom. In summary, the working performance of hysteretic dampers with circular opening is significantly better than that of the hysteretic damper with strip opening.

\subsection{Damage analysis}

The mechanical behaviors of tensile crack and compressive crush of concrete were simulated by the concrete damage plastic (CDP) model [23-25]. The stress-strain relationships under tension and compression are [26-28]: 


$$
\begin{gathered}
\sigma_{t}=\left(1-d_{t}\right) E_{0}\left(\varepsilon_{t}-\tilde{\varepsilon}_{t}^{\mathrm{pl}}\right), \\
\sigma_{c}=\left(1-d_{c}\right) E_{0}\left(\varepsilon_{c}-\tilde{\varepsilon}_{c}^{\mathrm{pl}}\right),
\end{gathered}
$$

where: $E_{0}$ is the initial elastic modulus; $\sigma$ is stress and $\varepsilon$ is strain. $\tilde{\varepsilon}_{t}^{\mathrm{pl}}$ is equivalent plastic strains in tension and $\tilde{\varepsilon}_{c}^{\mathrm{pl}}$ is equivalent plastic strains in compression; $d_{t}$ is tensile damage factor and $d_{c}$ is compressive damage factor.

In order to further analyze the influence of the arrangement of PT tendons and the type of hysteretic dampers on the seismic performance of the structures, the damage of concrete beams and the stresses of longitudinal reinforcements in the beams were compared and analyzed. The compressive and tensile damage factors of concrete beams in the first story under a PGA of $0.22 \mathrm{~g}$ are shown in Fig. 13. Also, the volume ratio of damaged elements in this

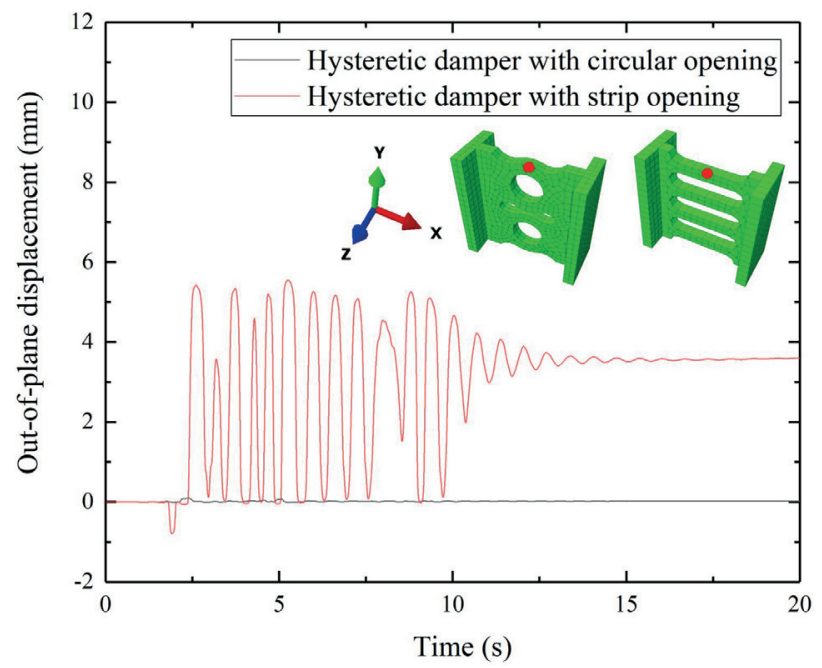

(a)

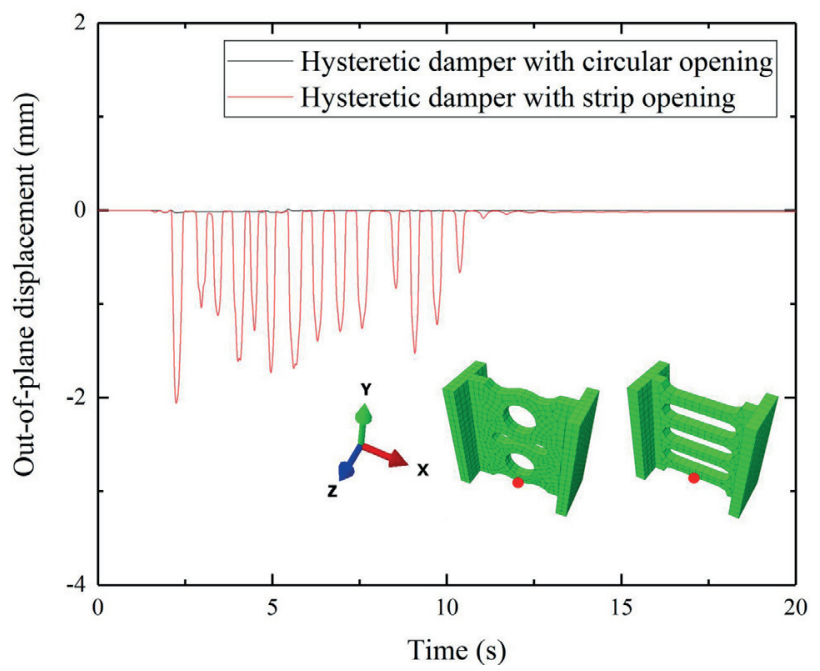

(b)

Fig. 12 Out-of-plane displacement of hysteretic dampers: (a) The top hysteretic dampers; (b) The bottom hysteretic dampers beam of different cases is shown in Table 5. For the convenience of comparison and discussion, the elements with DAMAGET $>0.05$ are named as damaged elements, and the elements with DAMAGET $>0.9$ are named as severely damaged elements. For the B1PT060S and B1PT060C frame, the compressive damage of the B1PT060C frame beam was slightly more serious than that of the B1PT060S frame beam. However, the tensile damage of the B1PT060S frame beam was slightly more serious than that of the B1PT060C frame beam. On the whole, there is no obvious difference between them. It is shown that the shape difference of the damper has little effect on the damage of the concrete beam.

For the B1PT100C and B1PT060C frame, the tensile damaged elements of B1PT100C frame beam increased by $4.20 \%$ compared with that of B1PT060C frame beam, and the severely damaged elements increased by $13.79 \%$. The compressive damaged elements of B1PT100C frame beam were $15.87 \%$ less than that of B1PT060C frame beam. It is indicated that for the frames with polygonal PT tendons, the vertical margin increased from $60 \mathrm{~mm}$ to $100 \mathrm{~mm}$, although the compressive damage of the frame

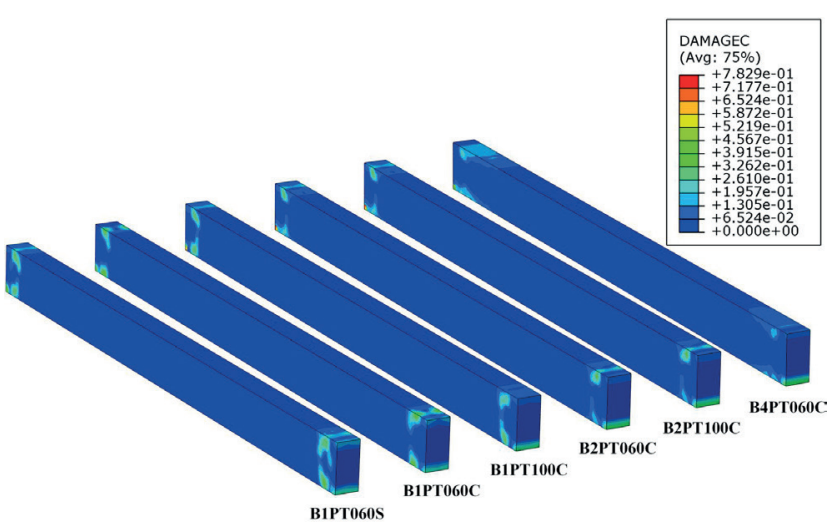

(a)

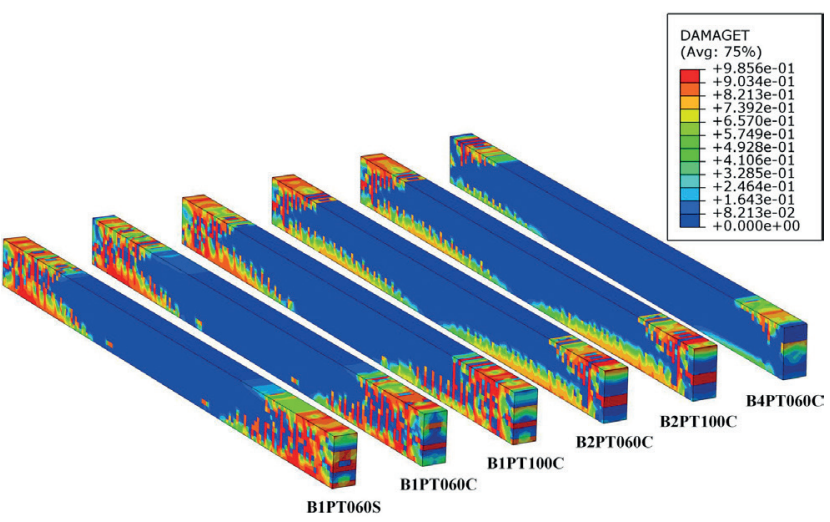

(b)

Fig. 13 Damage factors of concrete beams: (a) Compressive damage factor; (b) Tensile damage factor 
Table 5 Proportion of damaged elements

\begin{tabular}{lccc}
\hline Frame type & $\begin{array}{c}\text { Compressive } \\
\text { Damaged elements } \\
\text { (DAMAGEC }>0.05)\end{array}$ & $\begin{array}{c}\text { Tensile } \\
\text { Damaged elements } \\
\text { (DAMAGET > 0.05) }\end{array}$ & $\begin{array}{c}\text { Severely damaged elements } \\
\text { (DAMAGET }>0.9)\end{array}$ \\
\hline B1PT060S & $3.643 \%$ & $38.893 \%$ & $4.482 \%$ \\
B1PT060C & $3.714 \%$ & $38.286 \%$ & $4.143 \%$ \\
B1PT100C & $3.125 \%$ & $39.893 \%$ & $4.714 \%$ \\
B2PT060C & $2.786 \%$ & $37.268 \%$ & $2.464 \%$ \\
B2PT100C & $2.750 \%$ & $37.125 \%$ & $2.464 \%$ \\
B4PT060C & $4.714 \%$ & $12.250 \%$ & $0.429 \%$ \\
\hline
\end{tabular}

beam reduced to a certain extent, but the tensile damage significantly increased. The damages of concrete beams of the B2PT060C and B2PT100C frames were basically the same. It is indicated that for the frames with linear PT tendons, the vertical margin increased from $60 \mathrm{~mm}$ to $100 \mathrm{~mm}$, which had little effect on the stress state of concrete beams.

For the B4PT060C and B2PT060C frames, the compressive damaged elements of B4PT060C frame beam were $69.23 \%$ greater than that of B2PT060C frame beam. This is because the doubling of the prestressing force made the compressive stress state of the whole beam in a disadvantageous situation to a certain extent. The tensile damaged elements of B4PT060C frame beam were $67.13 \%$ less than that of B2PT060C frame beam, and the severely damaged elements decreased by $82.61 \%$. It shows that the doubling of the prestressing force can significantly reduce the tensile damage of concrete beams, but the adverse effect of excessive prestressing force on the compressive damage of concrete should also be concerned.

\subsection{Stress analysis}

The maximum stress time-history curves of top longitudinal reinforcements of the beam are shown in Fig. 14. The stress value was taken from the maximum stress of top longitudinal reinforcements of the beam in the first story. The residual stress of top longitudinal reinforcements in the beam of B1PT060S frame was 1.04 times that of the B1PT060C frame, and the residual stress of top longitudinal reinforcements in the beam of B1PT100C frame was 1.22 times that of the B1PT060C frame. Circular opening hysteretic dampers and strip opening hysteretic dampers had little effect on the stress of top longitudinal reinforcements in the beam. For the frames with polygonal PT tendons, the vertical margin increased from $60 \mathrm{~mm}$ to $100 \mathrm{~mm}$, and the stress of top longitudinal reinforcements in the beam increased significantly overall.

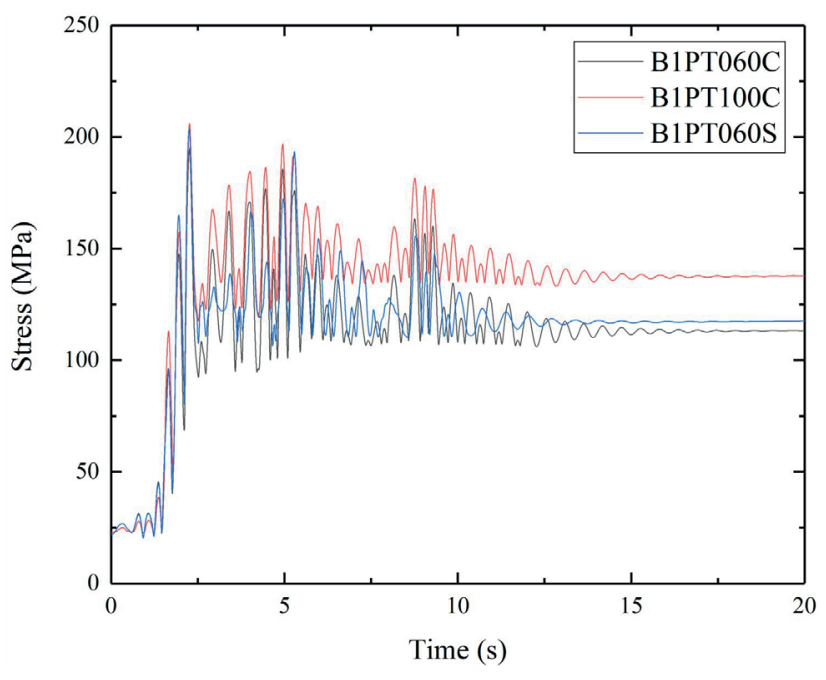

(a)

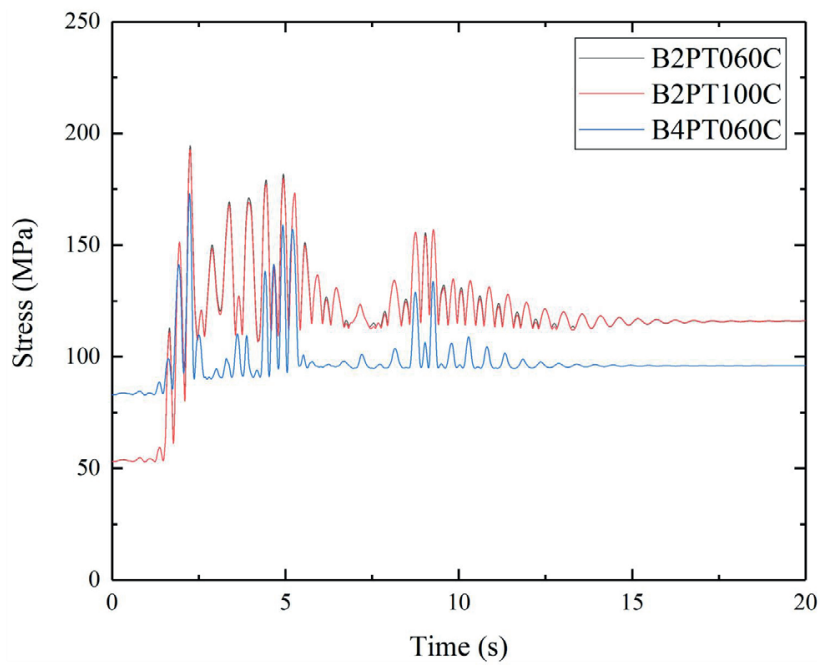

(b)

Fig. 14 Maximum stress time-history curves of top longitudinal reinforcements of beam: (a) The B1PT060C, B1PT100C, and B1PT060S

frames; (b) The B2PT060C, B2PT100C, and B4PT060C frames

However, the stresses of top longitudinal reinforcements in the beams of B2PT060C frame and B2PT100C frame were almost the same. 
The initial stress of top longitudinal reinforcements in the beam of B4PT060C frame was 1.56 times that of the B2PT060C frame, but its residual stress was $83 \%$ of that of the B2PT060C frame. Because the multiplication of prestressing force increased the restraining effect of the beam end, so the bending moment of the beam end was more borne by the longitudinal reinforcements. The concrete of B4PT060C frame had slight damage, and the residual rotation of the joint was small, so the residual stress of longitudinal reinforcements was not much different from the initial stress.

The maximum stress time-history curves of bottom longitudinal reinforcements of the beam are shown in Fig. 15. The stress of bottom longitudinal reinforcements was generally greater than that of the top longitudinal

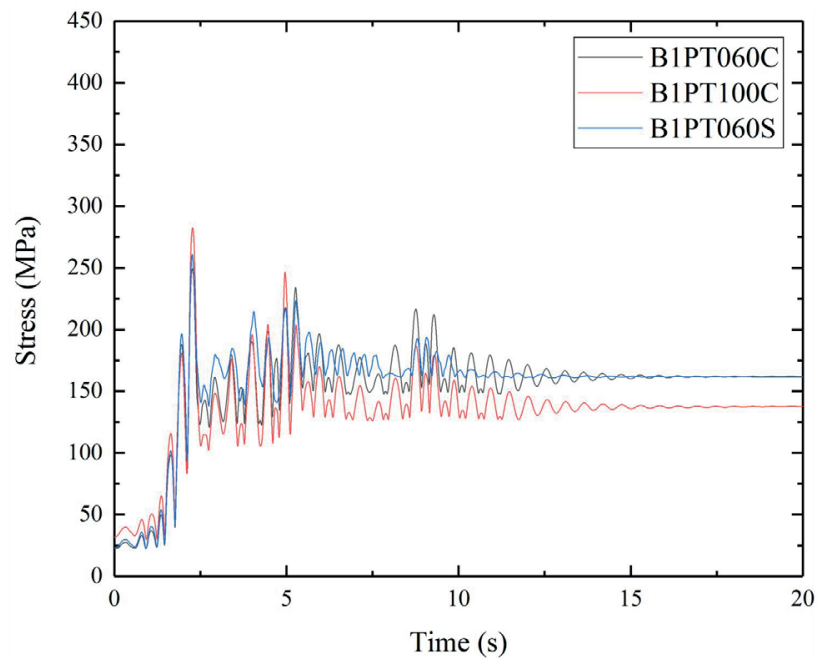

(a)

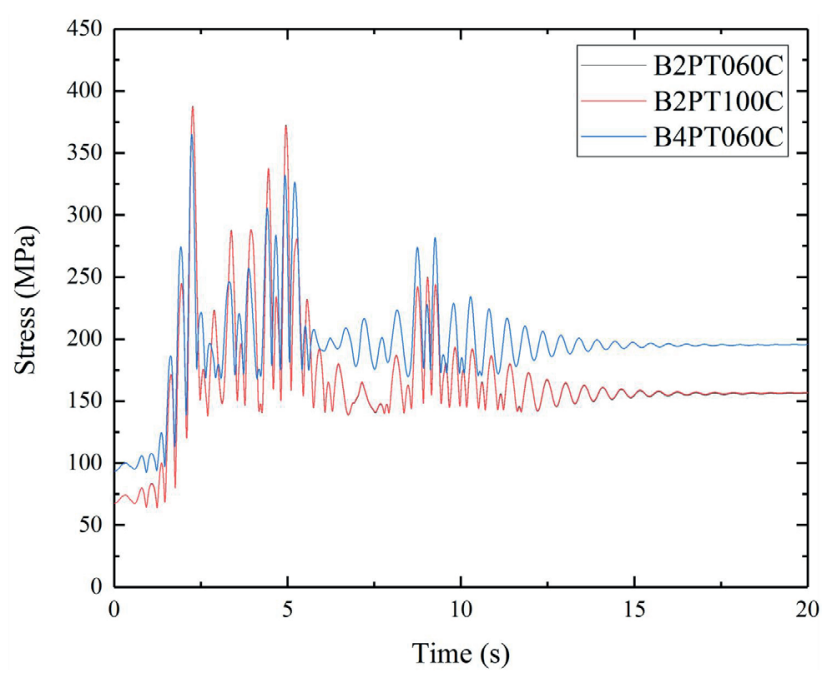

(b)

Fig. 15 Maximum stress time-history curves of bottom longitudinal reinforcements of beam: (a) The B1PT060C, B1PT100C, and B1PT060S frames; (b) The B2PT060C, B2PT100C, and B4PT060C frames reinforcements. The maximum stress of bottom longitudinal reinforcements of the beam using the polygonal PT tendons was significantly smaller than that of the beam using the linear PT tendons. The peak stress of bottom longitudinal reinforcements in the beam of B1PT060C frame was $64 \%$ of that of the B2PT060C frame, which indicates that the polygonal PT tendons can better bear the bending moment of the beam and reduce the stress of longitudinal reinforcements in the beam.

\section{Conclusions}

The finite element models of SCPCHD frames were established by ABAQUS, which adopted different layout types of PT tendons and different shapes of hysteretic dampers. Nonlinear dynamic time-history analyses were carried out to evaluate the differences in seismic performance of these SCPCHD frames. The global responses, energy dissipation, stress state of the components, and concrete damage of these frames were compared and analyzed, and the main results are summarized as follows:

- The layout types and vertical margin of PT tendons have little effect on the displacement response of the frame structure, and the displacement response of frame structure can be reduced by increasing the resultant force of PT tendons, but the reduction is not significant.

- Compared to linear PT tendons, polygonal PT tendons can better bear the bending moment of the beam and reduce the stress of longitudinal reinforcements in the beam.

- Under a PGA of $0.22 \mathrm{~g}$, the energy dissipation of the B1PT060C frame joint was 3.35 times that of the B1PT060S frame joint. The working performance of hysteretic dampers with circular opening is significantly better than that of the hysteretic damper with strip opening, because the out-of-plane buckling of strip opening hysteretic dampers under compression after yielding will result in partial failure of its function.

- The reduce effect of shortening the vertical margin on the tensile damage of beam concrete is obvious in the frame with polygonal PT tendons, but not obvious in the frame with linear PT tendons. The larger prestressing force can significantly reduce the tensile damage of concrete beams, but the adverse effect of excessive prestressing force on the compressive damage of concrete should also be concerned. 
- The displacement response of the B4PT060C frame with four PT tendons was relatively small, but the energy dissipation of the frame joint was poor. Therefore, the rational design of the prestressing force also plays a crucial role in the energy dissipation capacity of the SCPCHD frame.

\section{References}

[1] Wang, X., Ding, X., Wang, L., Wang, Y. "Fast assessment of earthquake loss and its application to the 2008 MS8.0 Wenchuan earthquake", Earthquake Science, 22(2), pp. 129-133, 2009.

https://doi.org/10.1007/s11589-009-0129-8

[2] Qin, W., Yao, H. "Characteristics of subevents and three-stage rupture processes of the 2015Mw 7.8 Gorkha Nepal earthquake from multiple-array back projection", Journal of Asian Earth Sciences, 133, pp. 72-79, 2017.

https://doi.org/10.1016/j.jseaes.2016.11.012

[3] Haseeb, M., Lu, X., Bibi, A., Khan, J. Z., Ahmad, I., Malik, R. "Construction of earthquake resistant buildings and infrastructure implementing seismic design and building code in northern Pakistan 2005 earthquake affected area", International Journal of Business and Social Science, 2(4), pp. 168-177, 2011.

[4] Cho, A. "Post-tsunami recovery and reconstruction: governance issues and implications of the Great East Japan Earthquake", Disasters, 38(s2), pp. 157-178, 2014.

https://doi.org/10.1111/disa.12068

[5] Stone, W. C., Cheok, G. S., Stanton, J. F. "Performance of hybrid moment-resisting precast beam-column concrete connections subjected to cyclic loading", Structural Journal, 92(2), pp. 229249, 1995.

https://doi.org/10.14359/1145

[6] Morgen, B. G., Kurama, Y. C. "A Friction Damper for Post-Tensioned Precast Concrete Moment Frames", PCI Journal, 49(4), pp. 112 133, 2004.

https://doi.org/10.15554/pcij.07012004.112.133

[7] Song, L.-L., Guo, T., Gu, Y., Cao, Z.-L. "Experimental study of a self-centering prestressed concrete frame subassembly", Engineering Structures, 88, pp. 176-188, 2015. https://doi.org/10.1016/j.engstruct.2015.01.040

[8] Guo, T., Xu, Z., Song, L., Wang, L. "Seismic Resilience Upgrade of RC Frame Building Using Self-Centering Concrete Walls with Distributed Friction Devices", Journal of Structural Engineering, 143(12), Article No. 04017160, 2017. https://doi.org/10.1061/(ASCE)ST.1943-541X.0001901

[9] Guo, T., Wang, L., Xu, Z., Hao, Y. "Experimental and numerical investigation of jointed self-centering concrete walls with friction connectors", Engineering Structures, 161, pp. 192-206, 2018. https://doi.org/10.1016/j.engstruct.2018.02.028

[10] Guo, T., Song, L., Cao, Z., Gu, Y. "Large-Scale Tests on Cyclic Behavior of Self-Centering Prestressed Concrete Frames", ACI Structural Journal, 113(6), pp. 1263-1274, 2016. https://doi.org/10.14359/51689248

\section{Acknowledgement}

This research was supported by the Fund for Distinguished Young Scientists of Jiangsu Province (Grant. BK20190013), the National Natural Science Foundation of China (Grants. 51978154 and 51608258), and the Scientific Research Foundation of the Graduate School of Southeast University (Grant No. YBPY1923).

[11] Ther, T., Kollár, L. P. "Design of rocking columns and arches subjected to earthquake excitation", presented at 16th European Conference on Earthquake Engineering 16ECEE, Thessaloniki, Greece, June, 18-21, 2018.

[12] Joó, A. L., Zsarnóczay, Á., Opoldusz, M., Kollár, L. P. "Applicability of modal response spectrum analysis on rocking structures", presented at 16th World Conference on Earthquake Engineering 16WCEE, Santiago, Chile, Jan. 9-13, 2017.

[13] Lengyel, G., Németh, R. K. "Symmetric free vibration of cracked arches of rigid discrete blocks", Engineering Structures, 162, pp. 51-59, 2018. https://doi.org/10.1016/j.engstruct.2018.01.058

[14] Lengyel, G., Németh, R. K. "The Mechanical Behavior of Ribs in Masonry Groin Vaults Subjected to Seismic Load", International Journal of Architectural Heritage, 13(6), pp. 886-900, 2018. https://doi.org/10.1080/15583058.2018.1491652

[15] MOHURD "GB50010-2010 Code for design of concrete structures", Ministry of Housing and Urban-Rural Development of the People's Republic of China, Beijing, China, 2010.

[16] MOHURD "GB50011-2010 Code for seismic design of buildings", Ministry of Housing and Urban-Rural Development of the People's Republic of China, Beijing, China, 2010.

[17] Huang, Y., Kang, T. H.-K., Ramseyer, C., Rha, C. "Background to multi-scale modelling of unbonded post-tensioned concrete structures", International Journal of Theoretical and Applied Multiscale Mechanics, 1(3), pp. 219-235, 2010. https://doi.org/10.1504/IJTAMM.2010.033601

[18] Kang, T. H.-K., Huang, Y., Shin, M., Lee, J. D., Cho, A. S. "Experimental and Numerical Assessment of Bonded and Unbonded Post-Tensioned Concrete Members", ACI Structural Journal, 112(6), pp. 735-748, 2015. https://doi.org/10.14359/51688194

[19] Huang, Y., Kang, T. H.-K. "Modeling of Sliding Behavior of Unbonded Tendons in Post-Tensioned Concrete Members", ACI Structural Journal, 115(4), pp. 1153-1164, 2018. https://doi.org/10.14359/51702066

[20] Qi, L., Xue, J. "Pseudo Dynamic Test and Time-History Analyses of Traditional-Style Steel Frame Structures", International Journal of Steel Structures, 18(2), pp. 402-416, 2018. https://doi.org/10.1007/s13296-018-0007-0

[21] Zhang, X.-C., Xue, J.-Y., Zhao, H.-T., Sui, Y. "Experimental study on Chinese ancient timber-frame building by shaking table test", Structural Engineering and Mechanics, 40(4), pp. 453-469, 2011. https://doi.org/10.12989/sem.2011.40.4.453 
[22] Guarracino, F., Walker, A. "Energy methods in structural mechanics: A comprehensive introduction to matrix and finite element methods of analysis", Thomas Telford, City, Country, 1999. https://doi.org/10.1680/emism.27572

[23] Du, X., Jin, L., Ma, G. "Numerical simulation of dynamic tensile-failure of concrete at meso-scale", International Journal of Impact Engineering, 66, pp. 5-17, 2014. https://doi.org/10.1016/j.ijimpeng.2013.12.005

[24] Kim, S.-M., Al-Rub, R. K. A. "Meso-scale computational modeling of the plastic-damage response of cementitious composites", Cement and Concrete Research, 41(3), pp. 339-358, 2011. https://doi.org/10.1016/j.cemconres.2010.12.002

[25] Xiao, J., Li, W., Corr, D. J., Shah, S. P. "Effects of interfacial transition zones on the stress-strain behavior of modeled recycled aggregate concrete", Cement and Concrete Research, 52, pp. 82-99, 2013. https://doi.org/10.1016/j.cemconres.2013.05.004
[26] Jin, L., Xu, C., Han, Y., Du, X. "Effect of End Friction on the Dynamic Compressive Mechanical Behavior of Concrete under Medium and Low Strain Rates", Shock and Vibration, 2016, Article ID 6309073, 2016.

https://doi.org/10.1155/2016/6309073

[27] Lubliner, J., Oliver, J., Oller, S., Oñate, E. "A plastic-damage model for concrete", International Journal of solids and Structures, 25(3), pp. 299-326, 1989.

https://doi.org/10.1016/0020-7683(89)90050-4

[28] Lee, J., Fenves, G. L. "Plastic-Damage Model for Cyclic Loading of Concrete Structures", Journal of Engineering Mechanics, 124(8), pp. 892-900, 1998 .

https://doi.org/10.1061/(ASCE)0733-9399(1998)124:8(892) 